\title{
Caminhos da Investigação Qualitativa na promoção da saúde
}

\author{
Elza Fátima Ribeiro Higa (iD \\ Faculdade de Medicina de Marília - Marília (SP) - Brasil \\ Emília Coutinho (iD \\ Escola Superior de Saúde de Viseu - Viseu - Portugal
}

Mara Quaglio Chirelli iD

Faculdade de Medicina de Marília - Marília (SP) - Brasil

\section{EDITORIAL}

A investigação qualitativa tem como particularidade a amplitude e a profundidade do conhecimento sobre um determinado fenômeno, no caminho da construção de novos saberes. Esta modalidade de pesquisa caracteriza-se por ser mais do tipo compreensivo e interpretativo de fenómenos ou situações particulares, construtivista e não positivista, de caracter intensivo e em profundidade em oposição ao extensivo, do tipo indutivo em oposição ao dedutivo, com uma abordagem mais naturalista e ecológica, do que correlacional e experimental ${ }^{(1-2)}$.

Ao se estruturar a cientificidade, o pesquisador começa a pensar sobre a natureza do objeto com a definição do problema e a base conceitual, nas quais são explicitadas as bases da pergunta "o quê?". Apresenta a relevância social da pesquisa por meio da justificativa da escolha do problema, respondendo a pergunta "porquê?". Essas duas primeiras indagações fornecem subsídios para que se estruture o objetivo que demonstra o lugar onde se pretende chegar com a investigação, ou seja, seu propósito, pela indagação "para quê?". E para alcançar o pretendido responde "como?". Desse modo, se organiza o método que delineia o caminho(3).

Neste sentido, considerando a importância da centralidade das questões de investigação - vale ressaltar que logo à partida o investigador tem que definir o que pretende fazer, conhecer a realidade em extensão ou em profundidade, observar ou também intervir. É o tipo de questão de investigação que determina o método a ser adotado, assim, o modo como a relidade é questionada pelo investigador determinará os objetivos e o método a ser seguido(2). $O$ tempo dedicado à definição e clarificação das questões de investigação é sempre bem empregado, pois nem todas as perguntas são questões de investigação ${ }^{(2,4)}$.

Os Participantes - são escolhidos em função das suas características e os que melhor conseguem retratar uma determinada realidade. No entanto, há a considerar a sua legitimidade, particularmente nos casos de entrevistas para decidirem se querem ter voz no estudo(2).

As Técnicas de recolha de dados - Em investigação qualitativa são técnicas clássicas de recolha de dados a entrevista, a observação e os grupos focais ${ }^{(5)}$. As entrevistas são preferencialmente as abertas, semiestruturadas, projetivas ou informais; a observação de campo, participante ou não participante é muito característica de certos contextos e habitualmente combinada com a entrevista; os grupos focais; e os painéis são também utilizados em investigação qualitativa ${ }^{(6)}$. Registam-se benefícios de um entendimento mais amplo da investigação particularmente com a triangulação de diferentes fontes de dados, diferentes momentos e diferentes métodos e técnicas que permitem obter um conhecimento mais robusto e profundo da problemática ${ }^{(2,6)}$.

O investigador como principal instrumento de recolha de dados - em investigação qualitativa o investigador deve se aproximar o suficiente para recolha de dados. Pelo corte epistemológico o investigador que esteve próximo para compreender distancia-se o suficiente para não enviesar os dados ${ }^{(2)}$.

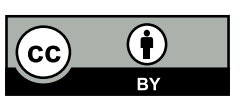

Este artigo está publicado em acesso aberto (Open Access) sob a licença Creative Commons, que permite uso, distribuição e reprodução em qualquer meio, sem restrições, desde que o trabalho seja corretamente citado.
Este editorial foi redigido pela comissão do $9^{\circ}$ e 10 Ciaiq Congresso Ibero-americano em Investigação Qualitativa, seguindo suas normas e formatação. 
A Saturação teórica dos dados e o número de participantes - o conceito de saturação dos dados ou número de participantes necessários ao estudo é variável, sendo uma questão que se coloca frequentemente entre os investigadores qualitativos. A saturação dos dados deve ser entendida não tanto em função das repetições que se possam encontrar ou do número de participantes envolvidos, mas quando as categorias estão bem estabelecidas, a diferença entre elas faz sentido e as relações estabelecidas permitem uma conclusão( ${ }^{(7)}$. Considerando o apontado por vários estudiosos recomenda-se uma média de vinte a trinta, sendo o mínimo de dez os participantes necessários para se poder obter dados sobre um determinado fenómeno, apesar da premissa ser mais a riqueza do discurso do que a quantidade(6).

As Técnicas de análise de dados - são diferentes as técnicas de análise de dados em investigação qualitativa. Para além da clássica técnica de "Análise de Conteúdo", existe uma diversidade de técnicas em função do método de investigação utilizado, como a Fenomenologia, Teoria Fundamentada ${ }^{(5)}$, Etnográfica, entre outras. Os dados são agrupados pela construção de categorias de análise - categorias indutivas ou categorias emergentes dos dados, com base nas observações, não são determinadas à priori pela literatura; categorias dedutivas ou pré-determinadas pela literatura, pautadas por conhecimentos gerais e preestabelecidos. Em investigação qualitativa, frequentemente se utilizam as categorias indutivas.

Desse modo, considerando a complexidade dos caminhos trilhados para o desenvolvimento da pesquisa qualitativa, este suplemento especial foi estruturado a partir dos trabalhos selecionados das $9^{\mathrm{a}}$ e $10^{\mathrm{a}}$ edições do Congresso Ibero - Americano de Investigação Qualitativa, constituído por oito artigos que transitam em seus diversos quês, porquês, para quês e como, que apresentam as fotografias das diversas realidades vivenciadas pelos autores, desvelando, desde os temas atuais que afligem a humanidade quanto os crônicos que permeiam o cuidado em saúde, sendo eles: "Análise das publicações sobre coronavírus utilizando redes bibliométricas"; "(In)compreensões dos gestores sobre as Práticas integrativas e Complementares na Atenção Primária à Saúde"; "Prevenção da Violência Doméstica: Importância da Intervenção do Enfermeiro Gestor de Caso - Revisão de Literatura"; "Os motivos que levam as pessoas idosas a recorrer frequentemente ao serviço de urgência"; 'Abordagem qualitativa como suporte para a elaboração de materiais educativos"; "Adesão tardia e as representações sociais relacionadas à assistência pré-natal"; "Unidade de saúde familiar amiga das pessoas idosas: perceção dos enfermeiros sobre os cuidados" e; "Doença falciforme: as faces do estigma e preconceito na construção da vulnerabilidade social".

Esperamos que os leitores possam trilhar por esses caminhos e se inspirarem a outras possibilidades da pesquisa qualitativa.

\section{REFERÊNCIAS}

1. Afonso N. Investigação Naturalista em Educação: Um guia prático e crítico. Vila Nova de Gaia: Fundação Manoel Leão; 2014.

2. Alarcão I. Dilemas do jovem investigador: Dos dilemas aos problemas. In: Costa AP, Souza FN, Souza DN. Investigação Qualitativa: Inovação, Dilemas e Desafios. $5^{a}$ ed. Oliveira de Azemeis: Ludomedia; 2019. p. 10324.

3. Minayo MCS, Deslandes SF, Gomes R. Pesquisa Social: teoria, método e criatividade. Petrópolis: Vozes; 2016.

4. Costa AP, Souza FN, Souza DN. Investigação Qualitativa: Inovação, Dilemas e Desafios. $5^{\mathrm{a}}$ ed. Oliveira de Azemeis: Ludomedia; 2019.

5. Amado J. Manual de Investigação Qualitativa em Educação. $2^{\mathrm{a}}$ ed. Coimbra: Imprensa da Universidade de Coimbra. [Internet] 2014 [acesso em 2021 Nov 06]. Disponível em:. https://digitalis-dsp.uc.pt/jspui/ bitstream/10316.2/35271/1/Manual\%20de\%20investiga\%C3\%A7\%C3\%A30\%20qualitativa\%20em\%20 educa\%C3\%A7\%C3\%A3o.pdf

6. Minayo MCS. Amostragem e saturação em pesquisa qualitativa: consensos e controvérsias. Revista Pesquisa Qualitativa. 2017;5(7):1-12. 
7. Baker SE, Edwards R. How many qualitative interviews is enough. Discussion Paper. National Centre for Research Methods. [Internet] 2012 [acesso em 2021 Nov 06]. Disponível em: https://eprints.ncrm.ac.uk/id/ eprint/2273/2012.

\section{Editoras Convidadas}

\section{Elza Fátima Ribeiro Higa}

Faculdade de Medicina de Marília - Brasil

hirifael@gmail.com

\section{Emília Coutinho}

Escola Superior de Saúde de Viseu, Instituto Politécnico de Viseu, Portugal ecoutinhoessv@gmail.com

\section{Mara Quaglio Chirelli}

Faculdade de Medicina de Marília, Brasil

marachirelli@gmail.com 